\title{
Estratégias da medicina preventiva de Geoffrey Rose
}

\author{
Rose's Strategies of Preventive Medicine
}

\section{Las estrategias de la medicina preventiva de Geoffrey Rose}

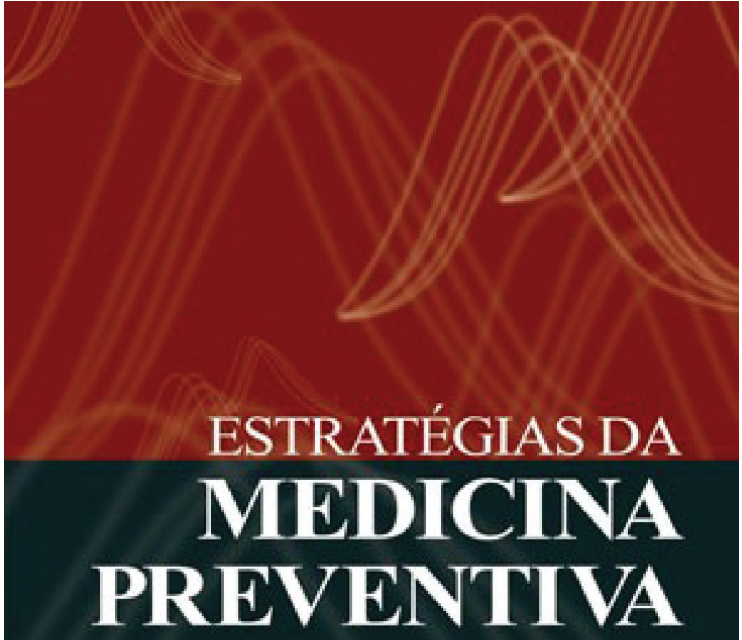

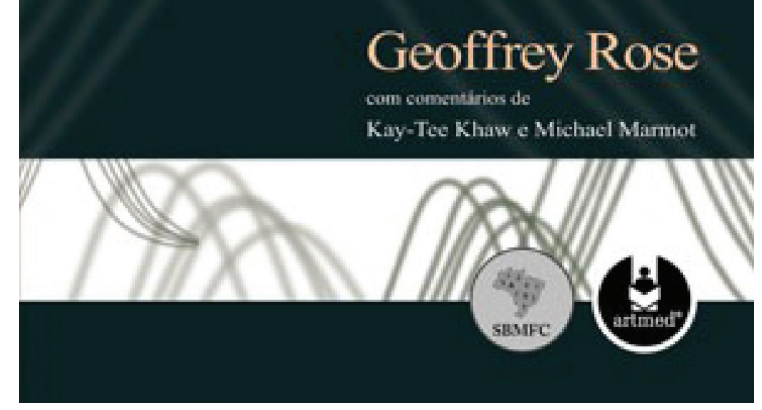

sam somentinios de

Kay-Tee Khaw e Michacl Marmot
Uma das atividades dos profissionais de saúde na prática dos serviços de atenção primária envolve a prevenção de doenças e a promoção da saúde. Essas atividades têm sido fortalecidas atualmente por meio de açóes programáticas de saúde e manejo das doenças crônicas não transmissíveis. Esse contexto reforça a importância de se entenderem as bases da prevenção, discutidas no livro Estratégias da Medicina Preventiva de Geoffrey Rose. ${ }^{1}$

Rose classifica a prevençáo de doenças em duas abordagens: a estratégia de alto risco (EAR) e a estratégia de amplitude populacional (EAP). A primeira refere-se ao processo de separação entre os indivíduos de alto risco e os demais. A segunda visa abranger a população como um todo.

A estratégia de alto risco parte de uma lógica binária de processo decisório que na medicina é denominada diagnose, ou seja, a pessoa tem ou não a condição a ser investigada. Em caso positivo, alguma intervenção lhe é oferecida; em caso negativo, 'deixa-se a pessoa em paz'. A EAR é muito atrativa e, tradicionalmente, mais lógica e adequada: primeiro, porque faz sentido tanto aos profissionais como aos pacientes, visto que ambos entendem mais facilmente o porquê da intervenção; segundo, por ser custo-efetiva, pois os recursos são direcionados àqueles que mais precisam; finalmente, porque se encaixa mais no cotidiano dos serviços, que geralmente operam na lógica do modelo individual do cuidado às doenças.

Existem, no entanto, algumas desvantagens desse tipo de intervenção: (1) tende-se a medicalizar a prevenção; (2) há que se manter o programa indefinidamente, pois não se intervém no problema de base; e (3) é difícil para aquele que recebe a intervenção quantificar seu real benefício, visto que se opera no campo da probabilidade (NNT: número necessário para tratar durante certo tempo para que uma pessoa se beneficie. Qual pessoa irá se beneficiar? Não sabemos). Porém, o mais frustrante da EAR
Palavras-chave: Medicina Preventiva Promoção da Saúde Prevenção de Doenças

\section{Keywords:}

Preventive Medicine Health Promotion Disease Prevention

Palabras clave: Medicina Preventiva Promoción de la Salud Prevención de Enfermedades

Fonte de financiamento: não há.

Conflito de interesses: não há.

Recebido em: 21/10/2014. Aprovado em: 16/02/2015. 
é seu pequeno impacto nos indicadores específicos da saúde pública para a condição sobre a qual se está intervindo, pois um grande número de pessoas submetidas a um pequeno risco produzirá mais casos da doença em questão do que um pequeno grupo com alto risco. Um exemplo de fácil compreensão é o caso da relação entre Síndrome de Down e idade gestacional. Gestantes abaixo de 30 anos, apesar de apresentarem baixo risco, geram metade das crianças nascidas com Síndrome de Down porque são em maior número, ao passo que gestantes de alto risco ( $\geq 40$ anos) geram somente 13\% das mesmas, pois a gestação ocorre com menos frequência nessa faixa etária. Isso produz um paradoxo: a estratégia de alto risco oferece pouco impacto sobre a população, uma vez que o grupo de alto risco representa uma pequena parcela da sociedade. Rose, por meio desse simples paradoxo, demostra que o pensamento binário de dividir entre doente e saudável não é tão efetivo, apesar de, intuitivamente, fazer mais sentido.

A proposta alternativa seria atuar sobre toda a população em vez de dividi-la entre os que têm alto risco e aqueles de risco habitual. Por isso a EAP pretende deslocar a média de distribuição do risco na população. Rose demostra esse conceito utilizando o comparativo de prevalências de parâmetros biomédicos entre diversas populaçóes. Em 1988, o Intersalt Cooperative Research Group ${ }^{2}$ forneceu dados padronizados de alta qualidade de hipertensão arterial e outras variáveis de mais de 10.000 homens e mulheres em 52 amostras populacionais de 32 países. A média dos níveis de pressão arterial sistólica variou $20 \mathrm{mmHg}$ entre as diferentes populaçôes, com prevalências de hipertensão variando desde nula no caso dos índios Ianomâmis a 33\% nos afro-americanos do Mississipi. Obviamente, esse achado tem grande importância para a saúde pública, pois, se conseguíssemos reduzir a prevalência do fenômeno distribuído na população como um todo, o impacto seria muito maior do que se intervíssemos individualmente. Assim, para uma redução de $10 \%$ no nível médio do colesterol sérico na população, se esperaria uma redução ao longo do tempo de $25 \%$ na mortalidade por doença arterial coronariana (p. 132). Ou seja, o governo, suas instituiçóes e a sociedade organizada deveriam focar suas medidas preventivas nas condiçóes sociais que afetam a população em geral e tirar um pouco o foco da intervenção sobre os indivíduos.

Alguns exemplos de medidas populacionais são: a adição de flúor à água, de ferro à farinha de trigo, a obrigatoriedade do uso de cinto de segurança e a proibição da ingesta de bebida alcoólica associada à direção. Tais medidas afetam a população como um todo, independente do risco basal individual. Por outro lado, a desvantagem da estratégia populacional é que cada participante individualmente tem pouco benefício, visto que sua susceptibilidade é baixa e a intervenção é disseminada na população.

Rose alerta que se o meio em que se vive está propiciando as condições desfavoráveis à saúde (por exemplo, o consumo de alimentos de alto teor calórico, ricos em sal, açúcares e gorduras saturadas e que geralmente têm preços mais acessíveis e forte apelo midiático para seu consumo), intervençóes individualizadas terâo pouco sucesso. Desse modo, orientar o indivíduo para que mude seus hábitos de vida ou alimentares costuma ter efetividade pequena ou de curta duração, pois a influência do meio é mais forte e tende a corromper propostas de estilo de vida saudável. Portanto, profissionais de saúde deveriam ser mais humildes e compreensivos quando seus pacientes não conseguem reduzir peso, baixar colesterol ou praticar alguma atividade física, principalmente quando trabalham em comunidades com realidade socioeconômica desfavorável. Isso não significa deixar de aconselhar e estimular os pacientes individualmente, mas sim ter a modéstia de reconhecer que, do ponto de vista da saúde pública, esse tipo de abordagem de alto risco tende a ser pouco efetivo.

Rose também propõe o que poderíamos chamar de prevenção 'a menos' e prevenção 'a mais'. A prevenção 'a menos' seria resgatar uma "saudabilidade" e/ou a sustentabilidade das condiçôes/modos de viver, pois se tem uma boa segurança sobre esse tipo de ação preventiva por meio da remoção de algumas exposiçôes "anormais" e fatores patogênicos (tais como tabagismo, poluição do ar e desvios alimentares recentemente adquiridos como o consumo de alimentos processados). Já a prevenção 'a mais' significa a introdução de um agente externo, uma droga, uma vacina, etc. Nesses casos, há necessidade de comprovação de evidências de altíssima qualidade, pois geralmente se está intervindo no corpo saudável, e o que se pretende é oferecer um potencial benefício futuro por meio de uma intervenção no presente.

A proposta de Rose pode ser aplicada tanto na prática dos serviços como na relação médico-paciente. A importância das ideias de Rose para a prática dos serviços da APS/ESF está no redirecionamento das atividades dos profissionais de saúde no processo de trabalho. Levando-se em conta a proposta apresentada de forma sucinta anteriormente, os profissionais de saúde deveriam ter a maior parte do seu tempo dedicada ao cuidado das pessoas em sofrimento e, complementarmente, para desenvolver ações de prevenção de doenças e promoção da saúde. Assim, facilitar o acesso ao cuidado deveria ser meta prioritária das equipes de ESF, mas o que costuma ocorrer é uma priorização de ações programáticas e rotinas de exames para pacientes assintomáticos por meio de check-ups. Atualmente, existe na APS uma exagerada valorizaçáo de açốes preventivas em detrimento do atendimento aos usuários, refletido no pouco espaço nas agendas dos profissionais para a demanda espontânea. 
Em relação à consulta médica, os conceitos apresentados por Rose também podem fortalecer a relação médico-paciente ao colocarem em segundo plano uma gama de ferramentas probabilísticas de cálculo de risco/mortalidade. A valorização dessas ferramentas de cálculo de risco é um típico exemplo da hipertrofia e da sobre valorização preventivista, bem como do uso inadequado da EAR. Essa abordagem converte pessoas sem lesão de órgáo alvo em pacientes de alto risco, por meio de modelos matemático-estatísticos populacionais, mas que na prática resultam em limitada capacidade preditiva de reais benefícios diante de um paciente em particular. Por isso, a EAR tende a medicalizar pessoas assintomáticas, o que aumenta os custos sociais ao converter pessoas saudáveis em doentes.

Por essas razões, o livro de Geoffrey Rose torna-se cada vez mais atual e relevante aos profissionais de saúde frente aos dilemas da prevençáo, sobretudo em relação à questão do sobrediagnóstico e do sobretratamento e à necessidade de se construir uma estratégia que fortaleça as bases da relação médico-paciente e a prevenção quaternária.

\section{Referências}

1. Rose G. Estratégias da medicina preventiva. Porto Alegre: Artmed; 2010. 192 p. ISBN: 978-85-363-2121-9

2. Intersalt Cooperative Research Group. Intersalt: an international study of electrolyte excretion and blood pressure. Results for 24 hour urinary sodium and potassium excretion. BMJ. 1988 Jul 30;297(6644):319-328. 